Article

\title{
Development and Properties of Polymeric Nanocomposite Coatings
}

\author{
Muddasir Nawaz ${ }^{1,+}$, Noor Yusuf ${ }^{1,+}{ }^{+}$, Sehrish Habib ${ }^{1}$, Rana Abdul Shakoor ${ }^{1, *}$, Fareeha Ubaid ${ }^{1}$, \\ Zubair Ahmad ${ }^{1}$ (D), Ramazan Kahraman ${ }^{2}$, Said Mansour ${ }^{3}$ and Wei Gao ${ }^{4}$ \\ 1 Center of Advanced Materials (CAM), Qatar University, 2713 Doha, Qatar; bie.mudasir@gmail.com (M.N.); \\ noorsyusuf@hotmail.com (N.Y.); sehrish.habib@qu.edu.qa (S.H.); fareeha.ubaid@qu.edu.qa (F.U.); \\ Zubairtarar@qu.edu.qa (Z.A.) \\ 2 Department of Chemical Engineering, Qatar University, 2713 Doha, Qatar; ramazank@qu.edu.qa \\ 3 Qatar Energy and Environment Research Institute, Hamad Bin Khalifa University, Qatar Foundation, \\ 34110 Doha, Qatar; smansour@hbku.edu.qa \\ 4 Department of Chemical and Materials Engineering, The University of Auckland, Private Bag 92019, \\ Auckland 1142, New Zealand; w.gao@auckland.ac.nz \\ * Correspondence: shakoor@qu.edu.qa; Tel.: +974-4403-6867 \\ + Authors with equal contributions.
}

Received: 11 April 2019; Accepted: 7 May 2019; Published: 10 May 2019

\begin{abstract}
Polymeric-based nanocomposite coatings were synthesized by reinforcing epoxy matrix with titanium nanotubes (TNTs) loaded with dodecylamine (DOC). The performance of the developed nanocomposite coatings was investigated in corrosive environments to evaluate their anti-corrosion properties. The SEM/TEM, TGA, and FTIR analysis confirm the loading of the DOC into the TNTs. The UV-Vis spectroscopic analysis confirms the self-release of the inhibitor (DOC) in response to the $\mathrm{pH}$ change. The electrochemical impedance spectroscopic (EIS) analysis indicates that the synthesized nanocomposite coatings demonstrate superior anticorrosion properties at $\mathrm{pH} 2$ as compared to $\mathrm{pH}$ 5. The improved anticorrosion properties of nanocomposite coatings at $\mathrm{pH} 2$ can be attributed to the more effective release of the DOC from the nanocontainers. The superior performance makes polymeric nanocomposite coatings suitable for many industrial applications.
\end{abstract}

Keywords: polymer; nanocontainers; nanocomposite coatings; self-healing; inhibitor; corrosion

\section{Introduction}

Carbon steel pipelines are used widely in the oil and gas industry for the transportation of liquids and gases. However, carbon steel pipelines suffer from poor corrosion resistance in solutions containing aggressive species like chloride ions [1-3]. Localized corrosion of pipelines in the oil and gas industry has been identified as a major factor causing pipeline failure worldwide, leading to mechanical failure and economic loss [4]. Localized corrosion includes pitting on carbon steel surface, which is harder to detect than uniform corrosion. Owing to the deleterious effect of corrosion, different techniques have been employed to improve the corrosion resistance of carbon steel [5-7]. Towards this goal, the corrosion resistance of steel has been improved by incorporation of insoluble, hard ceramic particles such as carbides and nitrides into steel [8]. On the other hand, corrosion mitigation using various types of corrosion inhibitors and coatings (organic and metallic) has also been conducted $[9,10]$. Organic inhibitors containing nitrogen and acetylenic alcohols have demonstrated promising efficiency [11-13]. Among various organic corrosion inhibitors, the dodecylamine (DOC) has been widely studied in aggressive acidic media $[14,15]$

Corrosion protection of metal surfaces by applying polymeric coatings is reliable and effective. Polymeric coatings provide a dense barrier for water and corrosive species from penetrating to the 
metal surface [16-18]. Epoxy resins are used for coating metals due to its strong chemical resistance and adhesion to metal surfaces [19]. However, when the epoxy-based barrier is damaged or scratched, the aggressive agents diffuse into the metal surface and cause corrosion [5]. Therefore, for control and delay, active corrosion suitable corrosion inhibitors are introduced into the epoxy coating [20]. Chromate containing coatings have been used for quite a time in the industry for the anticorrosion purpose. However, strict environmental and health regulations have been established due to the toxicity and cancer genic effects of chromates [20,21]. Furthermore, direct doping of organic corrosion inhibitors into the epoxy reduces the inhibition efficiency [20]. The decrease in inhibition efficiency is often noticed due to undesirable reactions between the inhibitor molecules and epoxy. Consequently, the smart coatings where the corrosion inhibitor is encapsulated into the nanocontainers and reinforced into the matrix are developed for solving this problem. The nanocontainers sense the corrosive dynamics and release the inhibitor on a required basis. Smart coatings are sensitive to different corrosive environmental changes such as $\mathrm{pH}$ change, temperature, mechanical damage, etc., and release the corrosion inhibitor when needed to mitigate corrosion [22]. Smart coatings are economically and environmentally friendly since the inhibitor is only released on a required basis. The corrosion inhibitors stored inside the inorganic nanocarriers are necessary to attain more efficient and reliable self-healing coatings that has been reported in previous studies. [23-25]. Several types of corrosion inhibitors and self-healing agents can be deposited on the surface or loaded inside hollow or porous inorganic carriers.

The most reported potential nanocontainers to host corrosion inhibitors are titanium dioxide nanotubes (TNTs) [26,27], mesoporous silica nanotubes (MSNTs) [28], and halloysite nanotubes (HNTs) [29]. Yuanchao et al. [16] evaluated the corrosion resistance performance of benzotriazole as corrosion inhibitor by loading it inside hollow silica particles and corrosion inhibitor was released in response to $\mathrm{pH}$ changes in the electrolyte. Poornima et al. [29] used halloysite nanocontainers to encapsulate the epoxy monomer and studied the self-healing and corrosion behavior of the HNT's doped epoxy coatings. Kinetics of releasing of corrosion inhibitors loaded within halloysite lumen was also studied by Lvov et al. [30]. Encapsulation and release of 8-hydroxyquinoline inside the $\mathrm{TiO}_{2}$ nanocontainers were studied by Ioannis et al. [31]. Falcon et al. [28] reported the release of dodecylamine inhibitor from mesoporous silica nanotubes. It was demonstrated that the release of dodecylamine (DOC) is sensitive to $\mathrm{pH}$ change. A faster release has been reported at $\mathrm{pH} 2.0$ than at $\mathrm{pH} 6.5$ and pH 9.0 [28]. Epoxy coatings are formulated with species, which enable them to hold back the water suction and capture the chlorides and carriers release the corrosion inhibitors. Nanocomposite coatings having different additives without detrimental effects on their barrier properties, and interactive combination of corrosion inhibitors are expressed in literature [32]. TNTs are attractive in the coating industry due to their affordability, high corrosion resistivity, and chemical stability $[26,33]$. TNTs have been synthesized using template-assisted method [34], anodizing of metal substrates [35,36], and the hydrothermal method [26]. However, the loading of TNTs with DOC and their performance evaluation under different corrosive conditions has not been studied yet.

In this work, we have synthesized TNTs using hydrothermal method [27], which were then loaded with DOC in a weight ratio of 5\%. TNTs loaded with DOC were then thoroughly dispersed into the epoxy matrix and coated on the steel substrate to develop smart coatings. Prepared TNTs and the nanocomposite coatings were then characterized. It was observed that the self-release of DOC from the nanocontainers (TNTs) is sensitive to the $\mathrm{pH}$ of the corrosive medium. The synthesized nanocomposite coatings demonstrate better corrosion resistance at $\mathrm{pH} 2$ than $\mathrm{pH}$. The improved properties of nanocomposite coatings at $\mathrm{pH} 2$ can be attributed to the more efficient release of the DOC from the nanocontainers. The decent corrosion resistance of the developed nanocomposite coatings makes them attractive for industrial applications. 


\section{Materials and Methods}

\subsection{Materials}

Titanium (IV) dioxide $\left(\mathrm{TiO}_{2}\right)$ also known as titania, hydrochloric acid (37\%), sodium hydroxide pallets, and ethanol were purchased from Sigma Aldrich, Darmstadt, Germany. Dodecyl amine (DOC, 98\% pure) was purchased from Alfa-Aesar, Ward Hill, MA, United States. Epoxy resin (815C) and EPIKURE as its curing agent were purchased from Sigma Aldrich, Darmstadt, Germany. Plates of plain carbon steel $(30 \mathrm{~L} \times 30 \mathrm{~W} \times 1.0 \mathrm{~T}) \mathrm{mm}^{3}$ used as substrates were locally purchased. The substrates were polished with silicon carbide ( $\mathrm{SiC}$ ) emery papers from 120 to 800 grit size and then rinsed thoroughly with distilled water.

\subsection{Synthesis of $\mathrm{TiO}_{2}$ Nanotubes (TNTs)-Nanocontainers}

Titanium oxide nanotubes (TNTs) or nanocontainers were synthesized using the hydrothermal method as reported in the literature. A total of $1.2 \mathrm{~g}$ of $\mathrm{TiO}_{2}$ powder was added into $20.0 \mathrm{ml}$ of $10 \mathrm{M}$ $\mathrm{NaOH}$ in Teflon beaker and stirred for $15 \mathrm{~min}$. The mixture was then put into Teflon-lined autoclave and heated at $130{ }^{\circ} \mathrm{C}$ for $10 \mathrm{~h}$ in a preheated oven. Precipitates obtained after centrifugation were washed with distilled water, dipped into $0.1 \mathrm{M} \mathrm{HCl}$ solution for $30 \mathrm{~min}$, and then washed again with distilled water until pH 7 was attained. Finally, the synthesized powder was dried at $80^{\circ} \mathrm{C}$ for $3 \mathrm{~h}$ to obtain TNTs.

\subsection{Loading of TNTs with an Inhibitor}

The synthesized $\mathrm{TiO}_{2}$ nanotubes (TNTs) were loaded with the corrosion inhibitor, dodecylamine (DOC), following the procedure adopted by Price et al. [37]. Then, $300 \mathrm{mg}$ of synthesized TNTs were to be mixed into a DOC solution $25.0 \mathrm{mg} / \mathrm{ml}$ in ethanol. After sonication, the solution was kept inside the vacuum jar for $24 \mathrm{~h}$ to complete the loading process; during the loading process, the air trapped in the nanotubes was replaced with DOC. A proposed schematic illustration of this encapsulation process is presented in Figure 1.

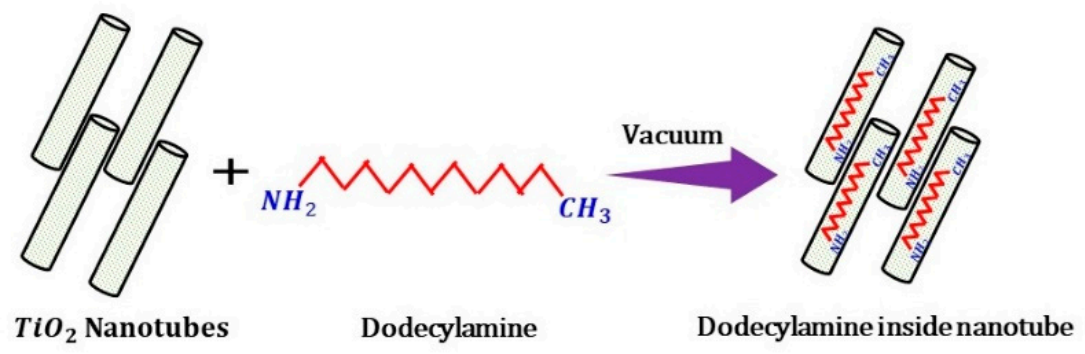

Figure 1. Schematic diagram showing the loading of dodecylamine (DOC) inside titanium oxide nanotubes (TNTs).

\subsection{Preparation of Nanocomposite Coatings}

The nanocomposite coatings were developed in several steps; (i) $5.0 \mathrm{wt}$.\% of DOC-loaded TNTs were thoroughly dispersed into the epoxy matrix resin, (ii) the addition of the hardener into the epoxy resin with the stoichiometric ratio of epoxy to the curing agent as 100:11, (iii) homogenization at room temperature, (iv) degassing of epoxy with sonication for $10 \mathrm{~min}$, (v) application of processed epoxy mixture on steel substrate by doctor blade, and (vi) curing of the developed coatings at room temperature for $48 \mathrm{~h}$.

\subsection{Characterization}

The morphological characterizations of synthesized TNTs and TNTs loaded with DOC were done by field emission scanning electron microscopy FE-SEM-Nova Nano-450 (FEI, New York, NY, USA) 
and transmission electron microscopy TEM TALOS F200X (FEI, New York, NY, USA). The structural and phase analysis of microcapsules was performed through X-ray diffraction analysis PANanalytical (Empyrean, Royston, United Kingdom) X'pert Pro $\mathrm{Cu}(\mathrm{K} \alpha)$ with a scanning rate of $2^{\circ} / \mathrm{min}$ and $2 \theta$ from scanning angle ranging between $10^{\circ} \leq 90^{\circ}$. Fourier transform infrared spectroscopy (FTIR) was also performed to confirm the loading of DOC in TNTs. The Spectrum was recorded in the range of $4000-500 \mathrm{~cm}^{-1}$ in the transmission mode using the FTIR Frontier (PerkinElmer, Waltham, MA, USA) instrument. TGA synchronization analyzer TG4000 (PerkinElmer) was used to investigate the thermal stability of as-synthesized TNTs and TNTs loaded with DOC. Thermal stability was studied in the temperature range from room temperature to $600{ }^{\circ} \mathrm{C}$ with a heating rate of $20{ }^{\circ} \mathrm{C} / \mathrm{min}$. Self-release of the inhibitor encapsulated in TNTs was investigated by UV-vis spectroscopic analysis (LAMBDA 650 UV/Vis Spectrophotometer (PerkinElmer). The amount of the released DOC from the TNTs was measured as a function of time at $\mathrm{pH} 2$ and 5 . The charges on TNTs before and after loading with DOC were determined to employ zeta potential equipment Zeta sizer, Nano ZSP (Malvern, Westborough, MA, USA) to check the possibility of their agglomeration. Electrochemical impedance spectroscopy $30 \mathrm{~K}$ BOOSTER Potentiostat/Galvanostat/ZRA (Gamry, Warminster, PA, USA) was carried out in $3.5 \mathrm{wt} . \%$ of $\mathrm{NaCl}$ solution at a $\mathrm{pH}$ level of 2 and 5 to evaluate the corrosion resistance of coatings. It was conducted within the frequency range of 0.1 to $100 \mathrm{KHz}$ at $\mathrm{OCP}$ and the rms signal was $10 \mathrm{mv}$.

\section{Results and Discussions}

\subsection{Morphological Analysis}

Figure 2 shows the (FE-SEM) and (HR-TEM) images of the as-synthesized TNTs and TNTs loaded with DOC. The tubular structure of as-synthesized TNTs is confirmed as shown in Figure 2a. The TNTs are relatively uniform in size and ordered in the stack. This result is in agreement with the results reported earlier in [38]. Figure $2 b$ shows the sticking of DOC on the outer sides of TNTs in addition to the loading of DOC into the TNTs. The hollow nature of TNTs is visible in Figure 2c. However, the blackening of hollow TNTs after loading indicates successful loading of TNTs with DOC (Figure 2d). The SEM images of the synthesized coatings shown in Figure 2e,f indicates that the coating surface is relatively uniform and scratch free and does not contain any significant defects. EDX elemental mapping of epoxy coatings are shown in Figure $2 \mathrm{~g}$, $\mathrm{h}$. It is clear from the elemental mapping that TNTs are properly mixed and homogenously distributed in the epoxy coating. The presence of $\mathrm{Ti}$ and $\mathrm{O}$ confirms the existence of $\mathrm{TiO}_{2}$ nanotubes. Furthermore, no presence of any foreign element or impurity in the EDX analysis confirming the high quality of the developed coatings.

\subsection{Structural Analysis}

XRD pattern of synthesized nanocomposite coatings containing $5 \mathrm{wt}$.\% TNTs loaded with DOC is shown in Figure 3. A broad peak at $2 \theta 20^{\circ}$ is a characteristic peak of epoxy showing its amorphous polymeric nature. Some other peaks of $\mathrm{TiO}_{2}$ are also seen in the pattern due to the use of TNTs as nanocontainers. No peaks of DOC were noticed in the XRD pattern. 

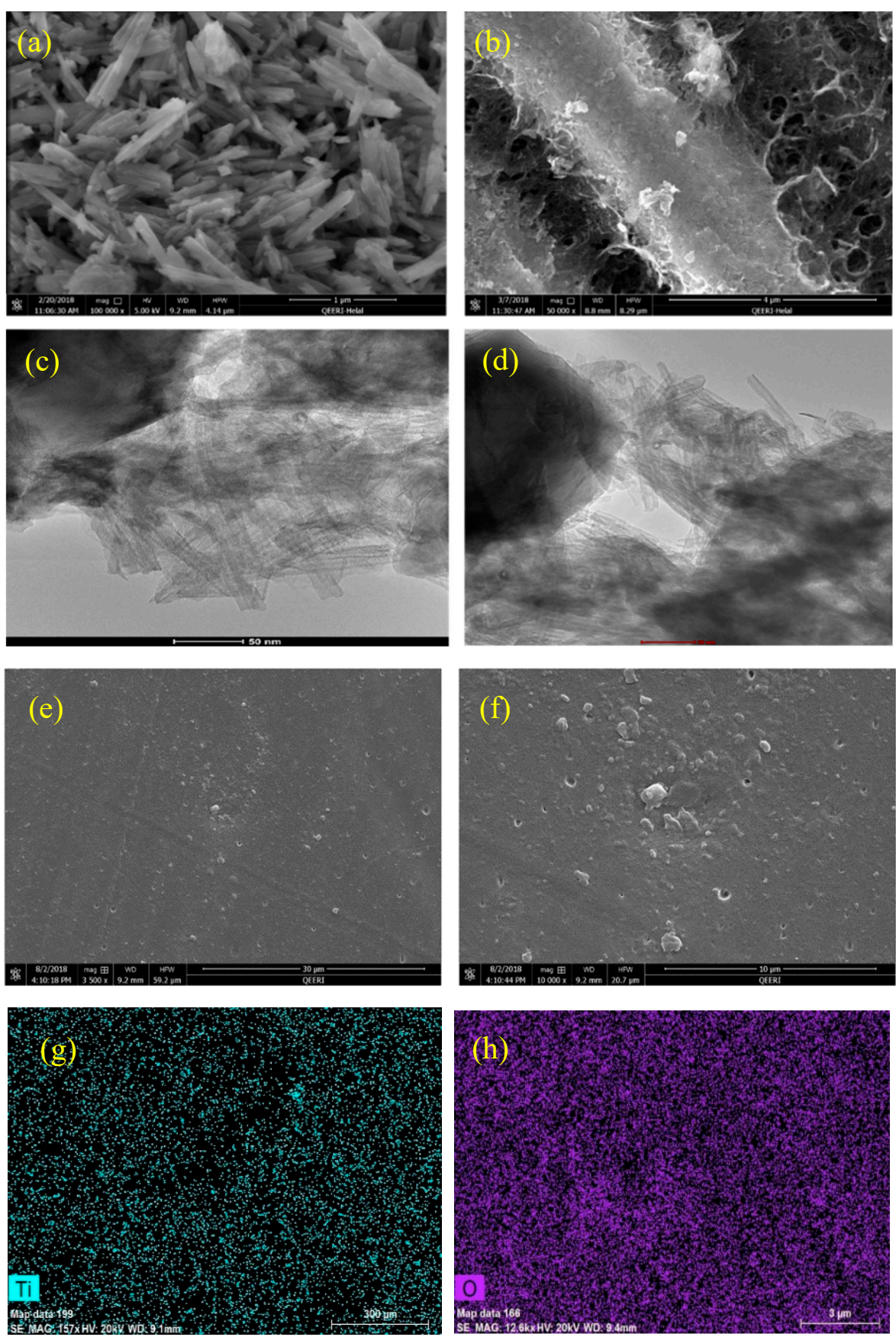

Figure 2. FE-SEM images: (a) As-synthesized TNTs, (b) TNTs loaded with DOC; HRTEM Images: (c) As-synthesized TNTs (d) TNTs loaded with DOC, (e,f) epoxy coating with 5 wt.\% loaded nanocontainers $(\mathbf{g}, \mathbf{h})$ EDX elemental mapping showing the presence of Ti and $\mathrm{O}$. 


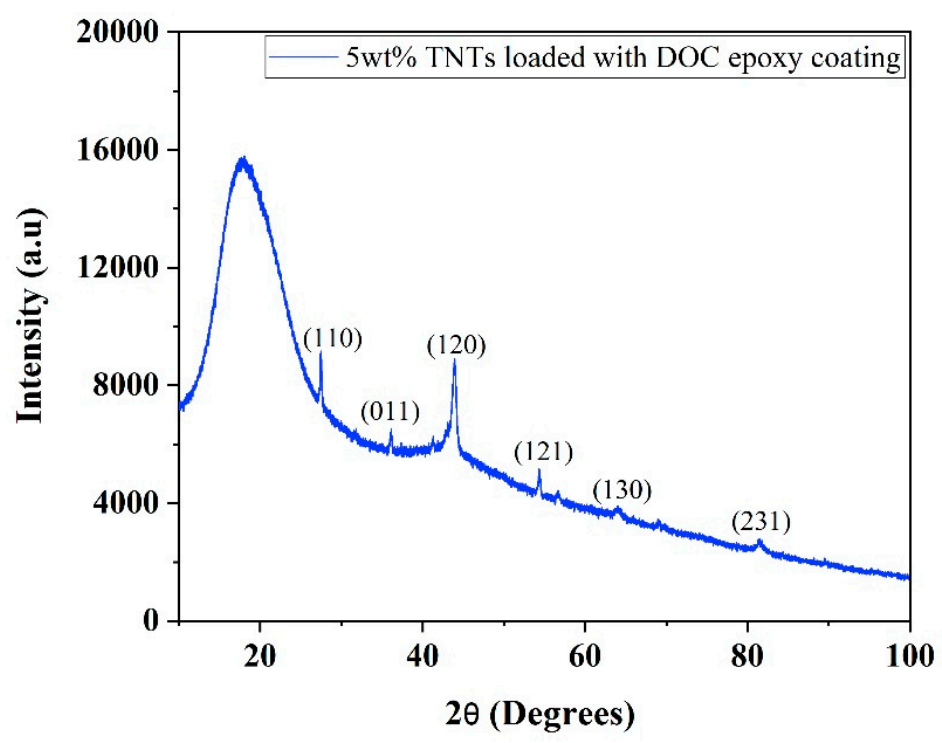

Figure 3. XRD pattern of as-synthesized nanocomposite epoxy coatings.

\subsection{FTIR Analysis}

FTIR spectra of as-synthesized TNTs and TNTs loaded with DOC are shown in Figure 4a, while FTIR spectra of Pure epoxy and as synthesized nanocomposite coatings are shown in Figure $4 \mathrm{~b}$. The FTIR analysis of two different spectra in Figure 4a shows that the characteristic band for TNT can be allocated to the bending and stretching vibration for Ti-O-Ti at around $660 \mathrm{~cm}^{-1}$ while in case of TNTs loaded with DOC, the first band observed around $3000 \mathrm{~cm}^{-1}$ and the peaks at $2915 \mathrm{~cm}^{-1}$ and $2847 \mathrm{~cm}^{-1}$ correspond to pure DOC which confirms the loading of TNTs with DOC in Figure 4a. The band at $2847 \mathrm{~cm}^{-1}$ corresponds to the $\mathrm{C}-\mathrm{H}$ stretching vibration [39]. The band at $1728 \mathrm{~cm}^{-1}$ is due to stretching vibration of $\mathrm{C}=\mathrm{O}$. The $\mathrm{N}-\mathrm{H}$ band is usually observed at about $1650 \mathrm{~cm}^{-1}$ [40]. However, in our study, the $\mathrm{N}-\mathrm{H}$ bending vibration observed at $1640 \mathrm{~cm}^{-1}$. This shift in band from its original position exhibits a hydrogen bonding nature while the band at $1459 \mathrm{~cm}^{-1}$ is due to $\mathrm{C}=\mathrm{C}$ stretching vibration. The bands at $1236 \mathrm{~cm}^{-1}$ and $1080 \mathrm{~cm}^{-1}$ are from $-\mathrm{N}$ bonding and $\mathrm{N}-\mathrm{H}$ deformation, respectively. The $\mathrm{C}-\mathrm{H}$ bending vibration can also be observed at $790 \mathrm{~cm}^{-1}$. Figure $4 \mathrm{~b}$ shows the FTIR spectra of blank epoxy and TNT loaded with DOC epoxy coatings. It has been seen that the peak at $1508 \mathrm{~cm}^{-1}$ corresponds to the $\mathrm{C}-\mathrm{C}$ stretching vibrations in aromatic. The peak at 973 corresponds to the characteristic peak of epoxide ring vibrations. The peak at $828 \mathrm{~cm}^{-1}$ refers to the $\mathrm{C}-\mathrm{H}$ plane deformation in aromatic. Moreover, the peak at $575 \mathrm{~cm}^{-1}$ corresponds to characteristics frequency of $\mathrm{C}_{6} \mathrm{H}_{4} \mathrm{X}_{2}$-para ( $X$ represents any functional group), which is also in accordance of previous reported literature [41].
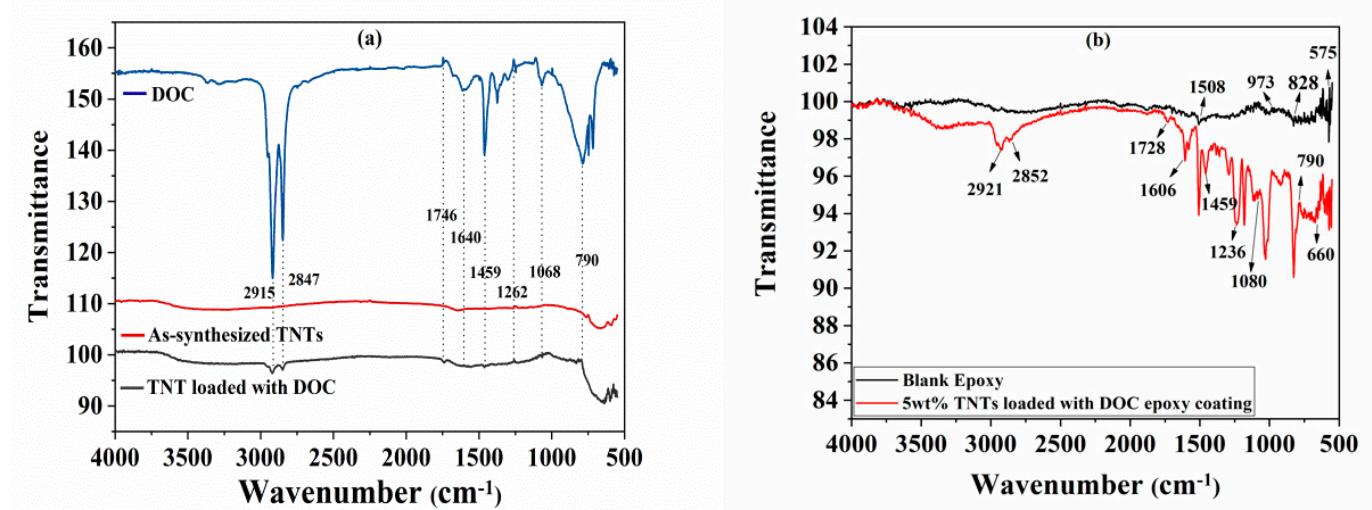

Figure 4. FTIR spectra of (a) as-synthesized TNTs, TNTs loaded with DOC, and pure DOC; (b) pure epoxy and epoxy coatings containing $5 \mathrm{wt}$.\% of TNTs loaded with DOC. 


\subsection{Thermal Stability}

Thermal analysis of as-synthesized TNTs, TNTs loaded with DOC, and developed nanocomposite coatings are compared in Figure 5. It is noticed that the nanocomposite coatings remain quite stable in the first stage from room temperature to about $200{ }^{\circ} \mathrm{C}$. However, there is a significant weight loss of the nanocomposite coatings observed in second stage, when the temperature is increased from $300{ }^{\circ} \mathrm{C}$ to $400{ }^{\circ} \mathrm{C}$. This weight loss can be attributed to the thermal degradation of epoxy. There is almost no weight loss observed for the nanocomposite coatings in the third stage $\left(400-600^{\circ} \mathrm{C}\right)$. As a comparison, TNTs remains stable (no weight loss) up to $600^{\circ} \mathrm{C}$ (being a ceramic phase). A small amount of weight loss $(0.58 \%)$ of TNTs is probably due to the removal of moisture content. Similarly, TNTs loaded with DOC shows no weight loss in the first stage but small weight loss observed in the second stage from about $200{ }^{\circ} \mathrm{C}$. A total of $1 \%$ weight loss occurred in TNTs encapsulated with DOC and this is probably due to the thermal decomposition of DOC.

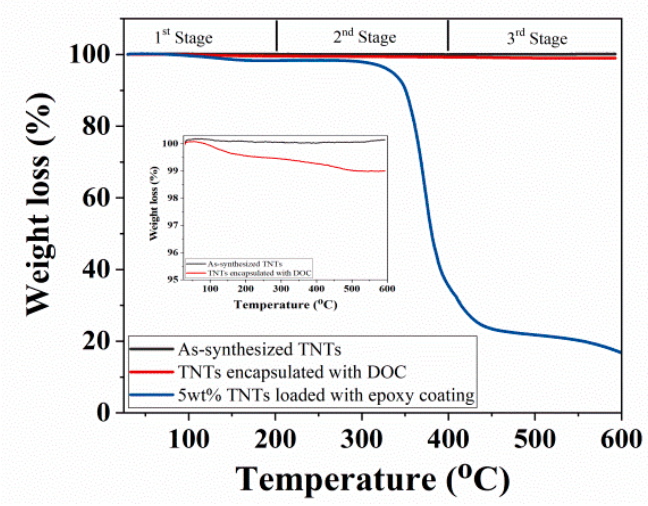

Figure 5. TGA analysis of as-synthesized TNTs, TNTs loaded with DOC, and nanocomposite.

\subsection{UV-vis Spectroscopy}

The release of DOC inhibitor from TNTs with respect to time at different $\mathrm{pH}$ values has been studied by UV-vis spectroscopy. Figure 6a shows the UV-vis spectroscopic analysis of TNTs loaded with DOC immersed into a $0.1 \mathrm{M} \mathrm{NaCl}$ solution at $\mathrm{pH} 2$ and 5 . Absorbance peaks showing the release of DOC from TNTs in response to $\mathrm{pH}$ change can be noticed. The absorbance value at 200 and $230 \mathrm{~nm}$ can be assigned to the presence of inhibitor in the solution. There is no significant absorbance value observed in the $24 \mathrm{~h}$, indicating no release of DOC from the TNTs. However, after the $48 \mathrm{~h}$, peak intensity value shows the release of inhibitor in response to $\mathrm{pH}$ change. There is an increase in the intensity of peaks after $72 \mathrm{~h}$, showing more release of inhibitor form TNTs. Almost the same peak intensity was observed at both $\mathrm{pH} 2$ and 5 but a slightly higher peak was observed at $\mathrm{pH} 2$ as compared to $\mathrm{pH}$ 5. This analysis indicates that the release of DOC from TNTs is time-dependent and sensitive to the aggressiveness of the corrosive medium. Local change in the $\mathrm{pH}$ during corrosion process act as the trigger for the release of DOC from TNT as initiation of corrosion activity is accompanied by local change of $\mathrm{pH}$ in anodic and cathodic sides [20]. TNTs loaded with DOC perform better in a more acidic environment. This is consistent with the previous studies [27]. The self-release of DOC from TNTs in response to $\mathrm{pH}$ change is also schematically shown in Figure $6 \mathrm{~b}$. 

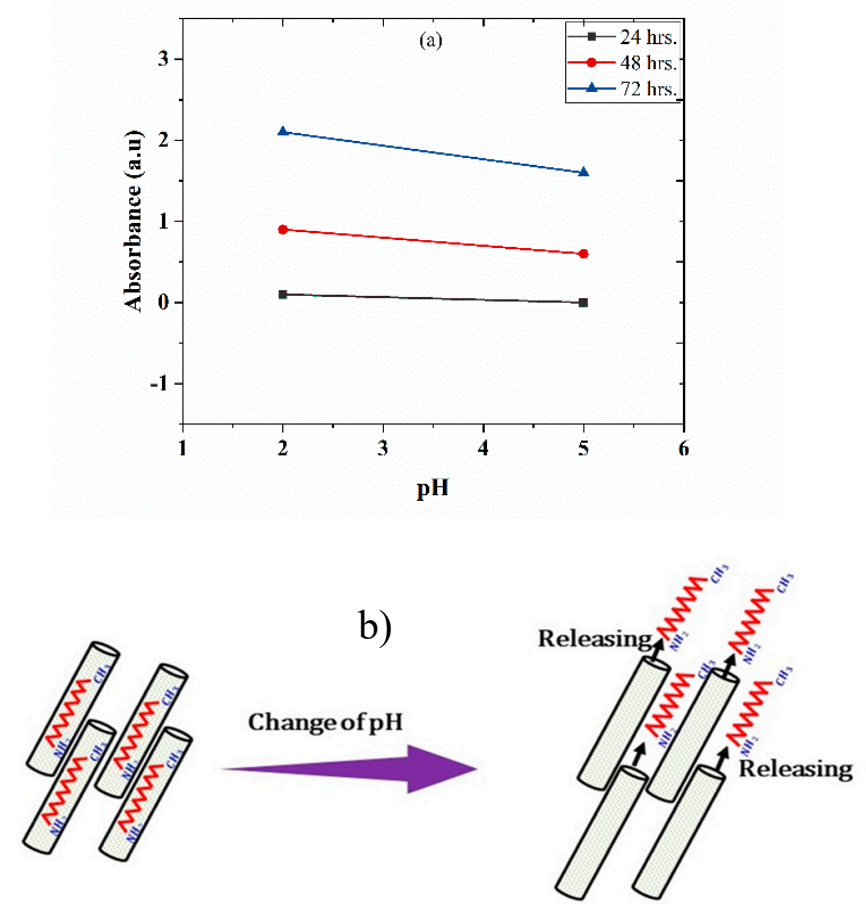

Figure 6. (a) UV spectra of TNTs encapsulated with DOC immersed in $0.1 \mathrm{M} \mathrm{NaCl}$ solution at $\mathrm{pH} 2$ and $\mathrm{pH} 5$ and (b) schematic diagram showing the self-release of DOC from TNTs in response to $\mathrm{pH}$ change.

\subsection{Zeta Potential Analysis}

The potential stability of the colloidal system was studied by zeta potential as a function of the TNTs concentration in deionized water. Figure 7 shows the zeta potential values of TNTs, DOC, and TNTs loaded with DOC. As-synthesized TNTs and TNTs loaded with DOC exhibit negative zeta potential. The zeta potential value for the as-synthesized TNTs is $-47.9 \mathrm{mV}$ while DOC has a slightly positive charge of $2 \mathrm{mV}$. Addition of the DOC into TNTs causes a slight decrease in the value of the zeta potential $(-54.2 \mathrm{mV})$. It should be noted that a zeta potential value greater than $30 \mathrm{mV}$ indicates good stability of the TNTs. This analysis suggests that no agglomeration takes place. Furthermore, the change in the concentration of the loaded TNT with DOC does not affect the zeta potential considerably. This is expected since previous studies have shown that a great shift in zeta potential values are observed for concentrations below $10^{-4}$ wt. $\%$ [42].

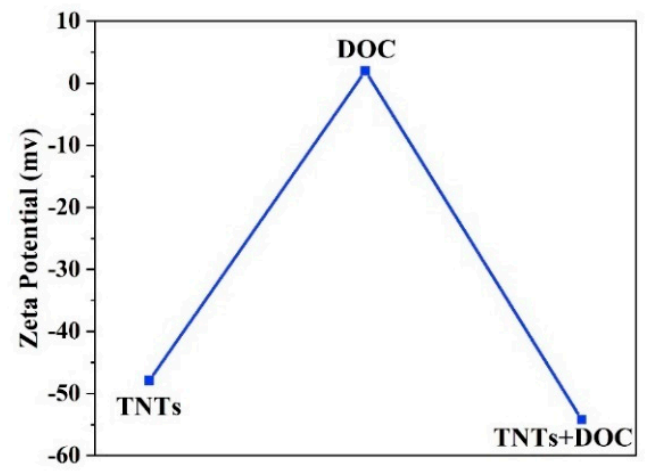

Figure 7. Zeta potential values of TNTs, DOC, and TNTs loaded with DOC. 


\subsection{Electrochemical Impedance Spectroscopy (EIS)}

Corrosion resistance behavior of nanocomposite coatings deposited on carbon steel was studied by EIS measurements. The coated samples were immersed in $3.5 \mathrm{wt} . \% \mathrm{NaCl}$ solution at $\mathrm{pH}$ values of 2 and 5. Corrosion resistance of the coated samples was studied up to 12 days of immersion. Figure $8 \mathrm{a}, \mathrm{b}$ shows the bode plots of nanocomposite coatings at pH 2 and 5 . Phase angles measured at $\mathrm{pH} 2$ and pH 5 are also shown in Figure 8c,d. Table 1 shows the electrochemical impedance parameters obtained from EIS analysis at $\mathrm{pH} 2$ and $\mathrm{pH}$ 5. The equivalent circuit used for fitting of EIS data is also shown in Figure 8e. At pH 2, the charge transfer resistance $\left(R_{\mathrm{ct}}\right)$ after one day of immersion for nanocomposite coatings is measured to be as $16.54 \times 10^{6} \Omega . \mathrm{cm}^{2}$ with a lower value of phase angle. Higher $R_{\mathrm{ct}}$ value shows that at the beginning nanocomposite coatings are able to protect themselves from corrosion attack. However, this value dropped down to $136.2 \times 10^{3} \Omega . \mathrm{cm}^{2}$ after four days of immersion in the solution indicating that the coatings have started losing their ability to resist the corrosive attack. At the later days of immersion, the $R_{\mathrm{ct}}$ value again shows an increase by reaching a maximum value of $148.2 \times 10^{6} \Omega . \mathrm{cm}^{2}$ with a major shift in the value of the phase angle (after 12 days of immersion). This increase in the $R_{\mathrm{ct}}$ value after four days, is due to the release of the DOC from the loaded nanotubes, which is forming a protective film in the scratched area, hence mitigating the corrosion phenomenon in that region. A schematic diagram showing the coatings healing mechanism is shown in Figure 9. The release of DOC from TNTs and the formation of a protective layer of DOC to inhibit corrosion attack is presented to explain the inhibition process.
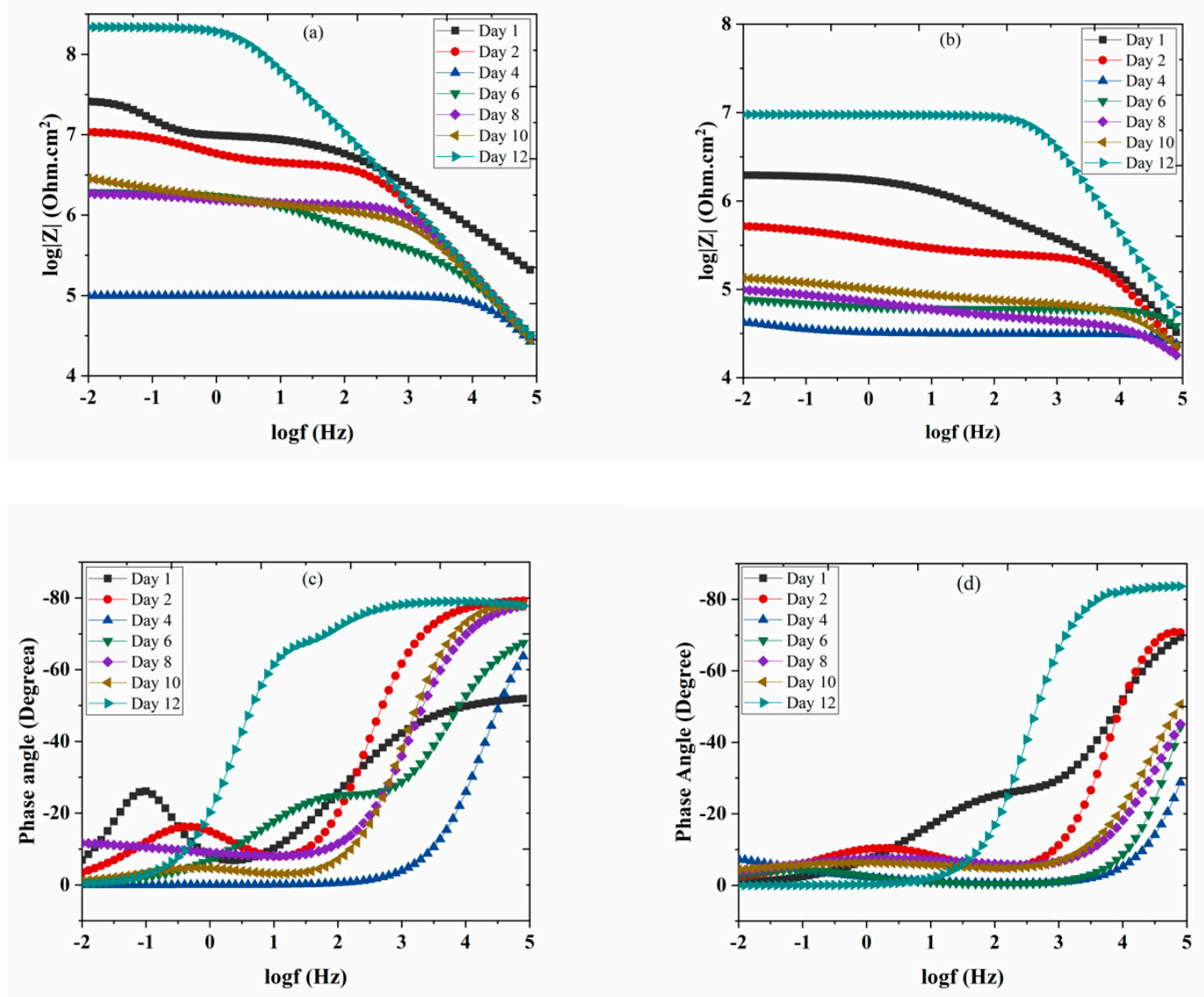

Figure 8. Cont. 


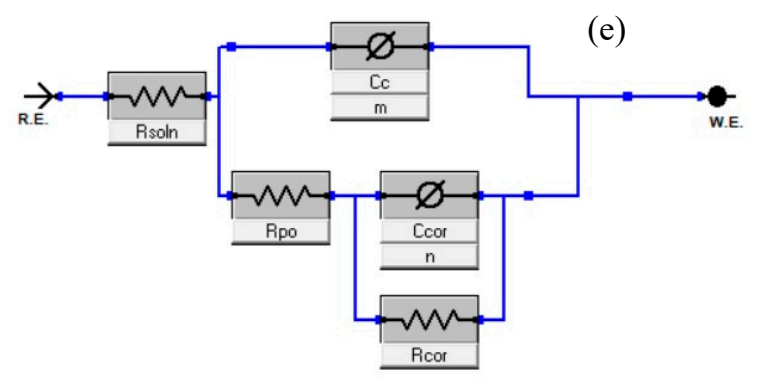

Figure 8. Bode graph of TNTs loaded with DOC (a), 5 wt. $\%$ at pH 2 (b), 5 wt. $\%$ at pH 5, phase angle measured of TNTs loaded with DOC (c), 5 wt. \% at pH 2 (d), 5 wt. $\%$ at pH 5 (e); equivalent circuit used for fitting of EIS data.

Table 1. Electrochemical impedance parameters from measured impedance data for coating of $5 \mathrm{wt} . \%$ TNTs loaded with DOC at pH 2 and 5.

\begin{tabular}{|c|c|c|c|c|c|}
\hline Coating & $\begin{array}{l}\text { Time } \\
\text { (Day) }\end{array}$ & $\begin{array}{c}R_{\mathrm{ct}} \\
\left(\Omega \cdot \mathrm{cm}^{2}\right)\end{array}$ & $\begin{array}{c}C_{\mathrm{C}} \\
\left(\mathrm{F} / \mathrm{cm}^{2}\right)\end{array}$ & $\begin{array}{c}R_{\mathrm{PO}} \\
\left(\Omega \cdot \mathrm{cm}^{2}\right)\end{array}$ & $\begin{array}{c}\text { Ccor } \\
\left(\mathrm{F} / \mathrm{cm}^{2}\right)\end{array}$ \\
\hline \multirow{7}{*}{$\begin{array}{l}5 \text { wt. } \% \text { TNTs } \\
\text { loaded with } \\
\text { DOC at pH } 2\end{array}$} & 1 & $16.54 \times 10^{6}$ & $2.128 \times 10^{-9}$ & $10.11 \times 10^{6}$ & $166.4 \times 10^{-9}$ \\
\hline & 2 & $6.914 \times 10^{6}$ & $287.8 \times 10^{-12}$ & $4.284 \times 10^{6}$ & $117.0 \times 10^{-9}$ \\
\hline & 4 & $136.2 \times 10^{3}$ & $319.5 \times 10^{-12}$ & $98.79 \times 10^{3}$ & $101.9 \times 10^{-6}$ \\
\hline & 6 & $1.561 \times 10^{6}$ & $811.1 \times 10^{-12}$ & $378.5 \times 10^{3}$ & $50.68 \times 10^{-9}$ \\
\hline & 8 & $28.79 \times 10^{6}$ & $325.4 \times 10^{-12}$ & $801.7 \times 10^{3}$ & $763.4 \times 10^{-9}$ \\
\hline & 10 & $520.0 \times 10^{3}$ & $252.2 \times 10^{-12}$ & $1.355 \times 10^{6}$ & $1.005 \times 10^{-6}$ \\
\hline & 12 & $148.2 \times 10^{6}$ & $301.1 \times 10^{-12}$ & $69.95 \times 10^{6}$ & $110.1 \times 10^{-12}$ \\
\hline \multirow{7}{*}{$\begin{array}{l}5 \text { wt. } \% \text { TNTs } \\
\text { loaded with } \\
\text { DOC at pH } 5\end{array}$} & 1 & $2.651 \times 10^{6}$ & $423.2 \times 10^{-12}$ & $265.4 \times 10^{3}$ & $34.41 \times 10^{-9}$ \\
\hline & 2 & $328.9 \times 10^{3}$ & $289.6 \times 10^{-12}$ & $231.9 \times 10^{3}$ & $1.986 \times 10^{-6}$ \\
\hline & 4 & $11.56 \times 10^{3}$ & $445.2 \times 10^{-12}$ & $32.01 \times 10^{3}$ & $278.8 \times 10^{-6}$ \\
\hline & 6 & $23.11 \times 10^{3}$ & $76.82 \times 10^{-12}$ & $59.49 \times 10^{3}$ & $77.51 \times 10^{-6}$ \\
\hline & 8 & $76.61 \times 10^{3}$ & $1.678 \times 10^{-9}$ & $39.52 \times 10^{3}$ & $10.13 \times 10^{-6}$ \\
\hline & 10 & $91.31 \times 10^{3}$ & $1.624 \times 10^{-9}$ & $65.25 \times 10^{3}$ & $9.279 \times 10^{-6}$ \\
\hline & 12 & $7.683 \times 10^{6}$ & $66.88 \times 10^{-12}$ & $1.798 \times 10^{6}$ & $699.21 \times 10^{-12}$ \\
\hline
\end{tabular}

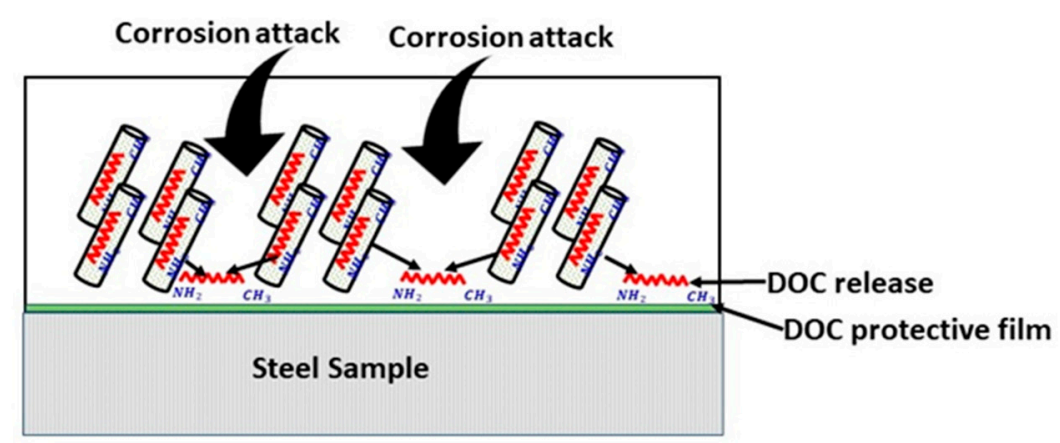

Figure 9. Schematic diagram of the healing mechanism in nanocomposite coatings.

The same trend has been observed during the EIS analysis of coated samples at $\mathrm{pH}$. After one day of immersion, the $R_{\mathrm{ct}}$ value of the coated sample was measured to be $2.651 \times 10^{6} \Omega . \mathrm{cm}^{2}$ while the $C_{\mathrm{c}}$ value was about $423.2 \times 10^{-12} \mathrm{~F} / \mathrm{cm}^{2}$ with a lower value of measured phase angle. The higher $R_{\mathrm{ct}}$ and lower $C_{c}$ value indicate good resistance of coatings against the corrosive attack. As the immersion time of the sample increases, the $R_{\mathrm{ct}}$ value at $\mathrm{pH} 5$ shows a decreasing trend until the fourth day of immersion. This decrease indicates that the release of DOC from the nanocontainers has not yet started and hence the coating has started to lose its protective ability. The corrosion resistance of the 
coating starts to increase after day 6 due to the release of the inhibitor. However, at day 10 and day 12 , $R_{\mathrm{ct}}$ value reaches to $91.31 \times 10^{3} \Omega . \mathrm{cm}^{2}$ and $7.683 \times 10^{6} \Omega . \mathrm{cm}^{2}$, respectively. With the increasing $R_{\mathrm{ct}}$ value, a major shift in the value of the phase angle has also been observed. This increase in the $R_{\mathrm{ct}}$ value indicates that the self-release of DOC has started from TNTs and, thus, it protects the coating surface from the corrosion attack by forming a protective layer over the surface. These observations suggest that the release of the inhibitor (DOC) from TNTs is time-dependent. Similar behavior was also confirmed by the displacement of phase angle from higher frequencies to lower frequencies in the bode diagram ( $\theta$ vs. $\log \mathrm{f}$ ). This trend demonstrates the further protective role of DOC released from the TNTs particles over the passage of time, which results in forming an adsorbed film on the surface of carbon steel. For the coated samples containing the same weight percentages of loaded nanocontainers, tested at $\mathrm{pH} 2$ and $\mathrm{pH} 5$, rendering to the results of releasing kinetics of releasing of DOC at different $\mathrm{pH}$ conditions, it can be concluded that for $\mathrm{pH} 2.0$, there is a greater amount of released inhibitor from the encapsulated TNTs. Hence, superior anticorrosive properties at $\mathrm{pH} 2$ are obtained when compared with $\mathrm{pH} 5$. These properties and releasing kinetics of the coatings make them attractive and are promising for the subsequent application of the loaded TNTs in anticorrosive smart coatings, as the corrosion is usually followed by alkaline or acidic $\mathrm{pH}$ shift. Thus, a release of the inhibitor in response to a $\mathrm{pH}$ change in the local surrounding environment occurs which can protect the steel substrate in the damaged area of the coating. A comparison of the present study with the already reported systems has been tabulated in Table 2, which demonstrates the efficiency and better anti-corrosive properties of the present study in comparison to the already reported similar systems.

For the coated samples containing the same weight percentages of loaded nanocontainers, tested at $\mathrm{pH} 2$ and $\mathrm{pH} 5$, EIS parameters confirm that the developed nanocomposite coatings demonstrate superior corrosion resistance at $\mathrm{pH} 2$ when compared with $\mathrm{pH}$ 5. The time-dependent release of DOC from the nanocontainers is more effective at $\mathrm{pH}$ 2. Therefore, this system is sensitive to the $\mathrm{pH}$ shift in the acidic region releasing the inhibitor on demand when the anodic process starts. Hence, more of the inhibitor is released from the nanocontainer in less time at $\mathrm{pH} 2$ as compared to $\mathrm{pH} 5$ [43]. This analysis shows that the release of DOC from TNTs is sensitive to the $\mathrm{pH}$ of the corrosive medium, which is consistent with previous studies [44]. This section may be divided by subheadings. It should provide a concise and precise description of the experimental results, their interpretation, as well as the experimental conclusions that can be drawn.

Table 2. Electrochemical impedance parameters from measured impedance data for coating of $5 \mathrm{wt} \%$ TNTs loaded with DOC at $\mathrm{pH} 2$ and 6.2.

\begin{tabular}{|c|c|c|c|c|}
\hline Sr. No & Coatings & Immersion time & $R_{\mathrm{ct}}$ & References \\
\hline \multirow{8}{*}{1} & \multirow{4}{*}{$\begin{array}{l}1 \text { wt.\% of nanocontainers (MS) with } \\
\text { encapsulated DOC at } \mathrm{pH} 2\end{array}$} & $1 \mathrm{hr}$. & $5.00 \times 10^{2} \Omega \cdot \mathrm{cm}^{2}$ & \multirow{8}{*}{ [43] } \\
\hline & & 3 hrs. & $6.50 \times 10^{2} \Omega \cdot \mathrm{cm}^{2}$ & \\
\hline & & 5 hrs. & $7.50 \times 10^{2} \Omega \cdot \mathrm{cm}^{2}$ & \\
\hline & & $16 \mathrm{hrs}$. & $2.500 \times 10^{3} \Omega \cdot \mathrm{cm}^{2}$ & \\
\hline & \multirow{4}{*}{$\begin{array}{l}1 \text { wt.\% of nanocontainers (MS) with } \\
\text { encapsulated DOC at pH } 6.2\end{array}$} & $1 \mathrm{hr}$. & $1.500 \times 10^{3} \Omega \cdot \mathrm{cm}^{2}$ & \\
\hline & & 3 hrs. & $1.750 \times 10^{3} \Omega \cdot \mathrm{cm}^{2}$ & \\
\hline & & 5 hrs. & $2.000 \times 10^{3} \Omega \cdot \mathrm{cm}^{2}$ & \\
\hline & & $16 \mathrm{hrs}$. & $3.000 \times 10^{3} \Omega \cdot \mathrm{cm}^{2}$ & \\
\hline \multirow{6}{*}{2} & \multirow{4}{*}{$\begin{array}{l}1 \text { wt. \% Halloysite nanotubes with } \\
\text { encapsulated DOC at pH } 2\end{array}$} & $1,2,3,5$ and $7 \mathrm{hrs}$. & $2.00 \times 10^{2} \Omega \cdot \mathrm{cm}^{2}$ & \multirow{6}{*}{ [45] } \\
\hline & & 18 hrs. & $5.50 \times 10^{2} \Omega \cdot \mathrm{cm}^{2}$ & \\
\hline & & $36 \mathrm{hrs}$. & $8.00 \times 10^{2} \Omega \cdot \mathrm{cm}^{2}$ & \\
\hline & & $48 \mathrm{hrs}$. & $1.100 \times 10^{3} \Omega \cdot \mathrm{cm}^{2}$ & \\
\hline & \multirow{2}{*}{$\begin{array}{l}1 \text { wt.\% Halloysite nanotubes with } \\
\text { encapsulated DOC at pH } 6.2\end{array}$} & $1,2,3,5$ and $7 \mathrm{hrs}$. & $1.700 \times 10^{3} \Omega \cdot \mathrm{cm}^{2}$ & \\
\hline & & 18,36 and $48 \mathrm{hrs}$. & $2.000 \times 10^{3} \Omega \cdot \mathrm{cm}^{2}$ & \\
\hline \multirow{4}{*}{3} & $1 \mathrm{wt} . \%$ of highly ordered Mesoporous silica & $1,2,3,5$ and $6 \mathrm{hrs}$. & $7.50 \times 10^{2} \Omega \cdot \mathrm{cm}^{2}$ & \multirow{4}{*}[28]{} \\
\hline & \multirow{3}{*}{$\begin{array}{c}1 \text { wt.\% of highly ordered Mesoporous silica } \\
\text { with encapsulated DOC at pH } 6.2\end{array}$} & & $1.130 \times 10 \mathrm{~s} \cdot \mathrm{cm}^{-2}$ & \\
\hline & & $1,2,3,5$ and $6 \mathrm{hrs}$. & $2.250 \times 10^{3} \Omega \cdot \mathrm{cm}^{2}$ & \\
\hline & & $24,26,28 \mathrm{hrs}$. & $3.250 \times 10^{3} \Omega \cdot \mathrm{cm}^{2}$ & \\
\hline
\end{tabular}




\section{Conclusions}

Polymeric nanocomposite coatings were developed by reinforcing epoxy matrix with TNTs loaded with DOC and their performance was evaluated in corrosive environments. Structural, morphological, and thermal analysis results confirm the successful loading of DOC into TNTs. It was also confirmed that the self-release of DOC from the TNTs is time and $\mathrm{pH}$ sensitive. The developed nanocomposite coatings demonstrate superior anticorrosion properties at $\mathrm{pH} 2$ when compared to $\mathrm{pH}$ 5. The improved electrochemical performance of nanocomposite coatings can be attributed to the excessive and more effective release of DOC from the TNTs at $\mathrm{pH} 2$. The tempting anticorrosion properties of synthesized polymeric nanocomposite coatings in the acidic environment make them attractive for industrial applications.

Author Contributions: The contributions of all authors are as follow. Conceptualization: M.N., F.U.; Methodology: M.N.; Software: S.M.; Validation: Z.A.; Formal Analysis: M.N., N.Y.; Investigation: M.N., S.H.; Data Curation: M.N., N.Y.; Writing-original draft presentation: M.N.; Writing-review and editing: S.H. and R.K.; Visualization: W.G.; Supervision: R.A.S.; Project administration: R.A.S.; Funding acquisition: R.A.S.

Acknowledgments: This publication was made possible by NPRP Grant 9-080-2-039 from Qatar National Research Fund (a member of the Qatar Foundation). Statements made herein are solely the responsibility of the authors. This research work was also partially supported by QU internal grant-QUCG-CAM-2018/2019-3. The Qatar National Library funded the publication cost of this article.

Conflicts of Interest: The authors declare no conflict of interest.

\section{References}

1. Krakowiak, S.; Darowicki, K.; Ślepski, P. Impedance of metastable pitting corrosion. J. Electroanal. Chem. 2005, 575, 33-38. [CrossRef]

2. Rasouli, S.; Danaee, I. Effect of preparation method on the anti-corrosive properties of nanocrystalline Zn-CoO ceramic pigments. Mater. Corros. 2011, 62, 405-410. [CrossRef]

3. Samiento-Bustos, E.; Rodriguez, J.G.G.; Uruchurtu, J.; Dominguez-Patiño, G.; Salinas-Bravo, V.M. Effect of inorganic inhibitors on the corrosion behavior of 1018 carbon steel in the $\mathrm{LiBr}+$ ethylene glycol $+\mathrm{H} 2 \mathrm{O}$ mixture. Corros. Sci. 2008, 50, 2296-2303. [CrossRef]

4. Cheng, F. Monitor safety of aged fuel pipelines. Nature 2016, 529, 156. [CrossRef]

5. Shirehjini, F.T.; Danaee, I.; Eskandari, H.; Zarei, D. Effect of nano clay on corrosion protection of Zinc-rich epoxy coatings on steel 37. J. Mater. Sci. Technol. 2016, 32, 1152-1160. [CrossRef]

6. Liu, S.; Gu, L.; Zhao, H.; Chen, J.; Yu, H. Corrosion resistance of graphene-reinforced waterborne epoxy coatings. J. Mater. Sci. Technol. 2016, 32, 425-431. [CrossRef]

7. Hou, J.; Zhu, G.; Xu, J.; Liu, H. Anticorrosion performance of epoxy coatings containing small amount ofinherently conducting PEDOT/PSS on hull steel in seawater. J. Mater. Sci. Technol. 2013, 29, 678-684. [CrossRef]

8. Beidokhti, B.; Dolati, A.; Koukabi, A.H. Effects of alloying elements and microstructure on the susceptibility of the welded HSLA steel to hydrogen-induced cracking and sulfide stress cracking. Mater. Sci. Eng. A 2009, 507, 167-173. [CrossRef]

9. Bahgat Radwan, A.; Sliem, M.H.; Okonkwo, P.C.; Shibl, M.F.; Abdullah, A.M. Corrosion inhibition of API X120 steel in a highly aggressive medium using stearamidopropyl dimethylamine. J. Mol. Liq. 2017, 236, 220-231. [CrossRef]

10. Hernández-Espejel, A.; Domínguez-Crespo, M.A.; Cabrera-Sierra, R.; Rodríguez-Meneses, C.; Arce-Estrada, E.M. Investigations of corrosion films formed on API-X52 pipeline steel in acid sour media. Corros. Sci. 2010, 52, 2258-2267. [CrossRef]

11. Verma, C.; Ebenso, E.E.; Vishal, Y.; Quraishi, M.A. Quraishi Dendrimers: A new class of corrosion inhibitors for mild steel in $1 \mathrm{M} \mathrm{HCl}$ : Experimental and quantum chemical studies. J. Mol. Liq. 2016, 224, 1282-1293. [CrossRef]

12. Mourya, P.; Banerjee, S.; Singh, M.M. Corrosion inhibition of mild steel in acidic solution by Tagetes erecta (Marigold flower) extract as a green inhibitor. Corros. Sci. 2014, 85, 352-363. [CrossRef] 
13. Finšgar, M.; Jackson, J. Application of corrosion inhibitors for steels in acidic media for the oil and gas industry: A review. Corros. Sci. 2014, 86, 17-41. [CrossRef]

14. De Damborenea, J.; Bastidas, J.M.; Vázquez, A.J. Adsorption and inhibitive properties of four primary aliphatic amines on mild steel in $2 \mathrm{M}$ hydrochloric acid. Electrochim. Acta 1997, 42, 455-459. [CrossRef]

15. Bastidas, J.M.; Polo, J.L.; Cano, E. Substitutional inhibition mechanism of mild steel hydrochloric acid corrosion by hexylamine and dodecylamine. J. Appl. Electrochem. 2000, 30, 1173-1177. [CrossRef]

16. Feng, Y.; Cheng, Y.F. An intelligent coating doped with inhibitor-encapsulated nanocontainers for corrosion protection of pipeline steel. Chem. Eng. J. 2017, 315, 537-551. [CrossRef]

17. Shchukin, D.G.; Möhwald, H. Smart nanocontainers as depot media for feedback active coatings. Chem. Commun. 2011, 47, 8730-8739. [CrossRef]

18. Shi, H.; Liu, F.; Han, E.H. Surface-engineered microcapsules by layer-by-layer assembling for entrapment of corrosion inhibitor. J. Mater. Sci. Technol. 2015, 31, 512-516. [CrossRef]

19. Moazeni, N.; Mohamad, Z.; Faisal, N.L.I.; Tehrani, M.A.; Dehbari, N. Anticorrosion epoxy coating enriched with hybrid nanozinc dust and halloysite nanotubes. J. Appl. Polym. Sci. 2013, 130, 955-960. [CrossRef]

20. Zheludkevich, M.L.; Tedim, J.; Ferreira, M.G.S. "Smart" coatings for active corrosion protection based on multi-functional micro and nanocontainers. Electrochim. Acta 2012, 82, 314-323. [CrossRef]

21. Fix, D.; Andreeva, D.V.; Lvov, Y.M.; Shchukin, D.G.; Möhwald, H. Application of inhibitor-loaded halloysite nanotubes in active anti-corrosive coatings. Adv. Funct. Mater. 2009, 19, 1720-1727. [CrossRef]

22. Zea, C.; Barranco-García, R.; Alcántara, J.; Simancas, J.; Morcillo, M.; de la Fuente, D. pH-dependent release of environmentally friendly corrosion inhibitor from mesoporous silica nanoreservoirs. Microporous Mesoporous Mater. 2018, 255, 166-173. [CrossRef]

23. Qiang, Y.; Zhang, S.; Xu, S.; Li, W. Experimental and theoretical studies on the corrosion inhibition of copper by two indazole derivatives in $3.0 \% \mathrm{NaCl}$ solution. J. Colloid Interface Sci. 2016, 472, 52-59. [CrossRef] [PubMed]

24. Andreeva, D.V.; Fix, D.; Möhwald, H.; Shchukin, D.G. Self-healing anticorrosion coatings based on pH-sensitive polyelectrolyte/inhibitor sandwichlike nanostructures. Adv. Mater. 2008, 20, 2789-2794. [CrossRef]

25. Singh, H.K.; Yeole, K.V.; Mhaske, S.T. Synthesis and characterization of layer-by-layer assembled magnesium zinc molybdate nanocontainer for anticorrosive application. Chem. Eng. J. 2016, 295, 414-426. [CrossRef]

26. Arunchandran, C.; Ramya, S.; George, R.P.; Kamachi Mudali, U. Corrosion inhibitor storage and release property of $\mathrm{TiO} 2$ nanotube powder synthesized by rapid breakdown anodization method. Mater. Res. Bull. 2013, 48, 635-639. [CrossRef]

27. Poornima Vijayan, P.; Al-Maadeed, M.A.S.A. TiO2nanotubes and mesoporous silica as containers in self-healing epoxy coatings. Sci. Rep. 2016, 6, 1-9.

28. Falcón, J.M.; Otubo, L.M.; Aoki, I.V. Highly ordered mesoporous silica loaded with dodecylamine for smart anticorrosion coatings. Surf. Coat. Technol. 2016, 303, 319-329. [CrossRef]

29. Vijayan, P.P.; Hany El-Gawady, Y.M.; Al-Maadeed, M.A.S.A. Halloysite nanotube as multifunctional component in epoxy protective coating. Ind. Eng. Chem. Res. 2016, 55, 11186-11192. [CrossRef]

30. Abdullayev, E.; Lvov, Y. Halloysite clay nanotubes for controlled release of protective agents delivered by ingenta. J. Nanosci. Nanotechnol. 2011, 11, 10007-10026. [CrossRef]

31. Kartsonakis, I.A.; Balaskas, A.C.; Kordas, G.C. Influence of cerium molybdate containers on the corrosion performance of epoxy coated aluminium alloys 2024-T3. Corros. Sci. 2011, 53, 3771-3779. [CrossRef]

32. Snihirova, D.; Lamaka, S.V.; Cardoso, M.M.; Condeço, J.A.D.; Ferreira, H.E.C.S.; De Fatima Montemor, M. $\mathrm{PH}$-sensitive polymeric particles with increased inhibitor-loading capacity as smart additives for corrosion protective coatings for AA2024. Electrochim. Acta 2014, 145, 123-131. [CrossRef]

33. Thi, D.; Phan, H.; Cuong, D.H.; Duc, L.M. Corrosion resistance and mechanical properties of TiO 2 nanotubes/epoxy coating on steel spcc-jisg 3141. Vietnam J. Sci. Technol. 2017, 55, 203-209.

34. Imai, H.; Takei, Y.; Shimizu, K.; Matsuda, M.; Hirashima, H. Direct preparation of anatase TiO2 nanotubes in porous alumina membranes. J. Mater. Chem. 1999, 9, 2971-2972. [CrossRef]

35. Yamamoto, R.; Sakai, K.; Takei, Y.; Yamasaki, N.Y.; Mitsuda, K. Performance of frequency division multiplexing readout system for AC-biased transition-edge sensor x-Ray microcalorimeters. J. Low Temp. Phys. 2014, 176, 453-458. [CrossRef] 
36. Gong, D.; Grimes, C.A.; Varghese, O.K.; Hu, W.; Singh, R.S.; Chen, Z.; Dickey, E.C. Titanium oxide nanotube arrays prepared by anodic oxidation. J. Mater. Res. 2001, 16, 3331-3334. [CrossRef]

37. Price, R.R.; Gaber, B.P.; Lvov, Y. In-vitro release characteristics of tetracycline HC1, khellin and nicotinamide adenine dineculeotide from halloysite; a cylindrical mineral. J. Microencapsul. 2001, 18, 713-722.

38. Bavykin, D.V.; Milsom, E.V.; Marken, F.; Kim, D.H.; Marsh, D.H.; Riley, D.J.; Walsh, F.C.; El-Abiary, K.H.; Lapkin, A.A. A novel cation-binding TiO2 nanotube substrate for electro- and bioelectro-catalysis. Electrochem. Commun. 2005, 7, 1050-1058. [CrossRef]

39. Chen, P.; Li, H.; Song, S.; Weng, X.; He, D.; Zhao, Y. Adsorption of dodecylamine hydrochloride on graphene oxide in water. Results Phys. 2017, 7, 2281-2288. [CrossRef]

40. Chakraborty, S.; Kar, S.; Dasgupta, S.; Mukhopadhyay, R.; Bandyopadhyay, S.; Joshi, M.; Ameta, S.C. Study of the properties of in-situ sodium activated and organomodified bentonite clay-SBR rubber nanocomposites-Part I: Characterization and rheometric properties. Polym. Test. 2010, 29, 181-187. [CrossRef]

41. Maity, P.; Kasisomayajula, S.V.; Parameswaran, V.; Basu, S.; Gupta, N. Improvement in surface degradation properties of polymer composites due to pre-processed nanometric alumina fillers. IEEE Trans. Dielectr. Electr. Insul. 2008, 15, 63-72. [CrossRef]

42. Tantra, R.; Schulze, P.; Quincey, P. Effect of nanoparticle concentration on zeta-potential measurement results and reproducibility. Particuology 2010, 8, 279-285. [CrossRef]

43. Falcón, J.M.; Batista, F.F.; Aoki, I.V. Encapsulation of dodecylamine corrosion inhibitor on silica nanoparticles. Electrochim. Acta 2014, 124, 109-118. [CrossRef]

44. Yang, M.; Wu, J.; Fang, D.; Li, B.; Yang, Y. Corrosion protection of waterborne epoxy coatings containing mussel-inspired adhesive polymers based on polyaspartamide derivatives on carbon steel. J. Mater. Sci. Technol. 2018, 34, 2464-2471. [CrossRef]

45. Falcón, J.M.; Sawczen, T.; Aoki, I.V. Dodecylamine-loaded halloysite nanocontainers for active anticorrosion coatings. Front. Mater. 2015, 2, 1-13. [CrossRef]

(C) 2019 by the authors. Licensee MDPI, Basel, Switzerland. This article is an open access article distributed under the terms and conditions of the Creative Commons Attribution (CC BY) license (http://creativecommons.org/licenses/by/4.0/). 